\title{
Water could reduce the hazard of cancer from spirits
}

\author{
E BOYLAND
} From the TUC Centenary Institute of Occupational Health, London School of Hygiene and Tropical Medicine,
London WCIE 7HT, UK

That alcohol consumption is associated with cancer has been suspected since Warren described a case of cancer of the tongue in a seaman who chewed tobacco which "in his case was generated by the long use of ardent spirits"... "Yet we know that tobacco is the common cause of cancer in the tongue and lip." Later it was shown that absinth drinkers had a high incidence of oesophageal cancer. ${ }^{2}$ The incidence rates of cancer of the oral cavity, oesophagus, and larynx were six to 12 times higher in men in the United States who smoked or chewed tobacco and drank more than six ounces of whisky a day than in abstainers; the effect of the same amount of alcohol taken as beer or wine was much less. ${ }^{3}$ Wynder emphasised that the high incidence of these tumours was associated with consumption of tobacco together with "hard liquor." In Puerto Rico there was a strong association between oesophageal cancer and consumption of rum. ${ }^{4}$ Similar effects of alcoholic drinks have been seen in Australia and Britain, ${ }^{5}$ Japan, ${ }^{6}$ and Washington DC. ${ }^{7}$ Some authors consider that "the international analysis suggests that ethyl alcohol itself, rather than any specific alcoholic beverage, is associated with the cancer." ${ }^{8}$ In France the relative risk caused by consuming $20 \mathrm{~g}$ tobacco and $80 \mathrm{~g}$ of alcohol a day was 44 times that of non-smokers consuming less than $10 \mathrm{~g}$ alcohol a day. ${ }^{10}$ "The importance of concentration was illustrated by the much greater risk among consumers of strong drink versus non-consumers within the same overall alcohol consumption categories. This suggests that alcohol plays the part of an irritant." 11 There are exceptionally high rates of cancer of the oesophagus in north west France where the risk varies with the amount of calvados consumed. ${ }^{12}$

The incidence of cancer of buccal cavity, pharynx, larynx, and oesophagus in Danish brewery workers were all about twice as high among workers who had free beer for 30 years as in the Danish population. ${ }^{13}$ It is not known whether these workers consume greater quantities of strong alcoholic beverages or tobacco than the reference population. There was no support

Accepted 18 July 1988 for a causal association between beer consumption and cancer of the colon and rectum in these brewery workers, although such an association seemed possible in the United States. ${ }^{14}$

Other causes of oesophageal cancer include opium residues in Iran, ${ }^{15}$ but in the western world the different spirits, whisky, calvados, and rum, all have the same effect and act before dilution with saliva which indicates that the active common constituent is ethanol in concentrations which occur in spirits. A possible mode of action of alcohol in causing cancer of the mouth and oesophagus as a tumour promoter is by reduction in interfacial tension in exposed tissues due to surface activity, causing cytolysis or increased fluidity of cell membranes. Alcohol is active as a carcinogen in the upper part of the alimentary tract where it is most concentrated. There are many different types of tumour promoters of which some are surface active substances including the detergents tweens, spans, and bile salts. ${ }^{16}$

Measurements of the effects of alcoholic beverages on interfacial tension between water and octyl alcohol showed that the surface activity varied directly with alcohol concentration except for beer and lager which had higher surface activity than expected from the alcohol content. ${ }^{17}$ This is due to the presence of humolones and other substances in hops which stabilise foam. These other surfactants may be associated with the possible increased incidence of colon and rectal cancer in beer drinkers. Ethanol damages cell membranes by its surface activity and being a small molecule soluble in water and lipids penetrates tissues quickly and so can act in the mouth and oesophagus more easily than large molecules. As a cause of cancer of the mouth and oesophagus, the concentration as well as the amount of alcohol is important. Alcohol also causes cirrhosis and cancer of the liver and for this, concentration is immaterial because dilution occurs before the alcohol reaches the liver. The urine of smokers and non-smoking patients with cirrhosis contains mutagens. ${ }^{18}$ The circulating mutagens acting as tumour initiators would increase the carcinogenic effect of the tumour promoting action of alcohol.

The epidemiological data show that the hazard of cancer of the upper alimentary tract is greater with 
consumers of spirits than with abstainers or with wine or beer drinkers. The risk of cancer among spirit drinkers would be reduced by not consuming alcohol and tobacco but also by diluting the whisky, gin, rum, calvados, or other strong or hard liquor with two or three volumes of water. Connoisseurs are divided about the benefits of adding water to whisky and brandy. There are, however, many who consider that the flavour of a good cognac or whisky may be better savoured if water is added, but a good spirit deserves good water. Perhaps the best procedure is to appreciate the bouquet and then add water to taste the flavour and reduce the carcinogenic hazard.

\section{References}

1 Warren JC. Surgical observations on tumours with cases and observations. Boston: Crocken and Brewster, 1837.

2 Lamy L. Etude de statistique clinique de 134 cas de cancer de l'oesophage et du cardia. Archives des Maladies de l'Appareil Digestif et de la Nutrition 1910;4:451-75.

3 Wynder EL, Mabuchi K. Etiological and preventive aspects of human cancer. Prev Med 1972;1:300-34.

4 Martinez I. Factors associated with cancer of the oesophagus, mouth and pharynx in Puerto Rico. J Natl Cancer Inst 1969;42:1069-94.

$5 \mathrm{McMichael}$ AJ. Increase in laryngeal cancer in Britain and Australia in relation to alcohol and tobacco consumption trends. Lancet 1978;i:1244-7.

6 Kono S, Ikeda M. Correlation between cancer mortality and alcoholic beverage in Japan. Br J Cancer 1979;40:449-55.

7 Pottern LM, Morris LE, Blot WJ, Ziegler RG, Fraumeni JF Esophageal cancer among black men in Washington DCD alcohol, tobacco and other risk factors. $J$ Natl Cancer Inst 1981;67:777-83.

8 Chilvers C, Fraser P, Beral V. Alcohol and oesophageal cancer: an assessment of the evidence from routinely collected data. Epidemiol Community Health, 1979;33:127-33.

9 Tuyns AJ. Cancer of the oesophagus: further evidence of the relation to drinking habits in France. Int J Cancer 1970;5 152-6.

10 Tuyns AJ, Pequinot G, Jensen OM. Le cancer de l'oesophagê en Ille-et-Vilaine en fonction des niveaux de consumptiond'alcohol et de tabac. Bull Cancer 1977;64:45-60.

11 Tuyns AJ, Pequinot G, Abbatucci JS. Oesophageal cancer and alcohol consumption: importance of type of beverage. Int $\boldsymbol{\omega}$ Cancer 1979;23:443-7.

12 Tuyns AJ, Masse G. Cancer of the oesophagus in Brittany: and incidence study in Ille-et-Vilaine. Int J Epidemiol 1975;4:55-9. 3

13 Jensen OM. Cancer mortality and causes of death among Danish $\triangle$ brewery workers. Lyon: International Agency Research on? Cancer, 1980.

14 Breslow NE, Enström JE. Geographic correlations between cancer mortality rates and alcohol-tobacco consumption in thew United States. J Natl Cancer Inst 1974;53:631-9.

15 Hewer T, Rose E, Ghadirian P, et al. Ingested mutagens from opium and tobacco pyrolysis products and cancer of the oesophagus. Lancet 1978;ii:494-6.

16 Boyland E. Surface active agents as tumour promoters. Envirom Health Perspect 1983;50:347-50.

17 Boyland E, Mohiuddin J. The surface activity of alcoholic beverages. IRCS Medical Science 1983;11:5-6.

18 Gelbart SM, Sontag SJ. Mutagenic urine in cirrhosis Lance 1980;i:894-6. 